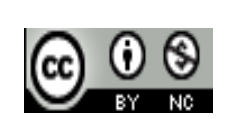

Jurnal Pendidikan Bahasa dan Sastra Indonesia is licensed under

A Creative Commons Attribution-Non Commercial 4.0 International License

\title{
Pengaruh Model Pembelajaran Reciprocal Learning Terhadap Hasil Belajar Keterampilan Menulis pada Siswa Kelas VIII B SMP Negeri 16 Singkawang Tahun Ajaran 2016/2017
}

\author{
Darmawan $^{1)}$, Gunta Wirawan ${ }^{2)}$, Lili Yanti ${ }^{3)}$ \\ 1.Program Studi Pendidikan Bahasa dan Sastra Indonesia, STKIP Singkawang, \\ E-mail: darmawan93@gmail.com \\ 2.Program Studi Pendidikan Bahasa dan Sastra Indonesia, STKIP Singkawang, \\ E-mail: gwirawan91@gmail.com \\ 3.Program Studi Pendidikan Bahasa dan Sastra Indonesia, STKIP Singkawang, \\ E-mail: liliyantiana18@gmail.com
}

\begin{abstract}
Abstrak. Tujuan penelitian ini adalah untuk mengetahui pengaruh model pembelajaran reciprocal learning terhadap keterampilan menulis rangkuman pada siswa kelas VIII B SMP Negeri 16 Singkawang. Metode yang digunakan dalam penelitian ini adalah metode eksprimen, dengan bentuk penelitian pre eksprimental design dan rancangan penelitian one-group posttes-pretes design. Teknik pengumpul data, yang digunakan adalah teknik observasi langsung, teknik komunikasi tidak langsung. Alat pengumpul data dalam penelitian ini adalah tes dan dokumentasi. Berdasarkan hasil pengolahan data dan analisis data dalam penelitian ini, maka dapat disimpulkan secara umum terdapat pengaruh model pembelajaran reciprocal learning terhadap hasil belajar keterampilan menulis rangkuman pada siswa SMP Negeri 16 Singkawang. Sedangkan secara khusus dapat disimpulkan (1) hasil belajar siswa dalam menulis rangkuman pada siswa kelas VIII B SMP Negeri 16 Singkawang sebelum menggunakan model reciprocal learning terdapat perbedaan yang signifikan pada skor pretes, hal ini dapat dilihat pada mean pretes sebesar 55,62 dan hasil diperoleh dari analisis data pretes masih dalam katagori cukup; (2) Hasil belajar siswa dalam menulis rangkuman pada siswa kelas VIII B SMP Negeri 16 Singkawang sesudah menggunakan model reciprocal learning terdapat perbedaan yang signifikan pada skor postes hal ini dapat dilihat pada mean posttes sebesar 80,22 tergolong dalam katagori baik; dan (3) dengan diketahuinya ada pengaruh yang signifikan maka dalam hal ini pengaruh model reciprocal learning terhadap hasil belajar siswa menulis rangkuman pada siswa kelas VIII B SMP Negeri 16 Singkawang dinyatakan berpengaruh hal ini di buktikan dengan hasil uji effect size dengan hasil 3,08 kategori tinggi.
\end{abstract}

Kata Kunci : Reciprocal learning, keterampilan menulis.

\section{PENDAHULUAN}

Kurikulum Tingkat Satuan Pendidikan (KTSP) adalah kurikulum operasional yang disusun, dikembangkan, dan dilaksanakan oleh setiap satuan pendidikan dengan memperhatikan standar kompetensi dan kompetensi dasar yang dikembangkan Badan Standar Nasional Pendidikan (BSNP). Kurikulum Tingkat Satuan Pendidikan merupakan strategi pengembangan kurikulum untuk mewujudkan sekolah yang efektif, produktif, dan berprestasi.

Pengajaran bahasa bertujuan untuk meningkatkan kemampuan berbahasa siswa. Keterampilan berbahasa meliputi empat aspek yaitu menyimak, berbicara, membaca, dan menulis. Keempat keterampilan berbahasa tersebut saling berhubungan satu dengan lainnya. Keterampilan menulis merupakan satu di antara keterampilan berbahasa yang sangat penting. Menulis dapat diartikan sebagai kegiatan penyampaian pesan dengan menggunakan bahasa tulis sebagai alat medianya (Saddhono, Kundharu dan St, Y. Slamet, 2012).

Menulis rangkuman merupakan pembelajaran yang menyajikan karangan yang panjang dalam bentuk singkat. Menulis rangkuman adalah kemahiran dalam menyajikan suatu karangan yang panjang dalam bentuk yang singkat menggunakan pengetahuan yang diperoleh melalui 
pembelajaran sehingga dapat mengaplikasikanya dalam praktik (Purnama, 2014). Berdasarkan permasalahan yang ada peneliti memilih kelas VIII B dikarenakan menurut sumber data yang diperoleh dari guru mata pelajaran bahasa Indonesia hasil menulis siswa masih rendah, selain itu peneliti juga ingin membantu guru yang bersangkutan dalam meningkatkan hasil belajar siswa terutama dalam keterampilan menulis rangkuman. Alasan peneliti memilih SMP Negeri 16 Singkawang adalah belum pernah diterapkanya model pembelajaran reciprocal learning di SMP Negeri 16 Singkawang khususnya pada mata pelajaran bahasa Indonesai dalam keterampilan menulis.

Model pembelajaran sebagai alternatif untuk memberikan variasi pada proses pembelajaran adalah model pembelajaran reciprocal learning. Huda (2015) menyatakan bahwa "Reciprocal learning merupakan model pembelajaran yang digunakan untuk meningkatkan pemahaman terhadap suatu topik, dalam pembelajaran ini guru serta murid memegang peranan penting pada tahap dialog suatu topik (teks)". Reciprocal learning merupakan belajar efektif dengan cara membaca bermakna, merangkum, bertanya, representasi dan hipotesis (Ngalimun, 2016).

Skripsi penelitian ini lebih menekankan pada beberapa aspek penilaian yaitu isi, organisasi, kosakata, penggunaan bahasa, dan mekanik. Isi menyangkut informasi yang disampaikan relevan dan tuntas, organisasi menyangkut gagasan yang disampaikan jelas, padat, dan urutanya logis sesuai dengan struktur rangkuman. Kosakata menyangkut pemilihan kosakata yang tepat. Penggunaan bahasa menyangkut pada kalimat dan keefektifan kalimat. Mekanik menyangkut penulisan kata yang sesuai dengan ejaan yang disempurnakan.

Berdasarkan identifikasi masalah tersebut maka masalah umum dalam penelitian ini adalah "Apakah terdapat pengaruh Model pembelajaran Reciprocal Learning terhadap hasil belajar keterampilan menulis pada siswa kelas VIII B SMP Negeri 16 Singkawang tahun ajaran 2016/2017?”. Adapun sub-sub masalah yang akan dirumuskan dalam penelitian ini adalah (1) Bagaimanakah kemampuan menulis rangkuman isi buku ilmu pengetahuan populer sebelum menggunakan model reciprocal learning pada siswa kelas VIII B SMP Negeri 16 Singkawang tahun ajaran 2016/2017? (2) Bagaimanakah kemampuan menulis rangkuman isi buku ilmu pengetahuan populer sesudah menggunakan model reciprocal learning pada siswa kelas VIII B SMP Negeri 16 Singkawang tahun ajaran 2016/2017? (3) Bagaimanakah pengaruh model reciprocal learning terhadap menulis rangkuman isi buku ilmu pengetahuan populer pada siswa kelas VIII B SMP Negeri 16 Singkawang tahun ajaran 2016/2017?.

Tujuan penelitian ini adalah (1) Untuk mengetahui kemampuan menulis rangkuman buku ilmu pengetahuan populer sebelum menggunakan model reciprocal learning pada siswa kelas VIII B SMP Negeri 16 Singkawang tahun ajaran 2016/2017, (2) Untuk mengetahui kemampuan menulis rangkuman buku ilmu pengetahuan populer sesudah menggunakan model reciprocal learning pada siswa kelas VIII B SMP Negeri 16 Singkawang tahun ajaran 2016/2017, dan (3) Untuk mengetahui pengaruh model reciprocal learning terhadap menulis rangkuman buku ilmu pengetahuan populer pada siswa kelas VIII B SMP Negeri 16 Singkawang tahun ajaran 2016/2017.

\section{METODE}

Metode yang digunakan dalam penelitian ini adalah metode eksperimen. Metode eksprimen adalah satu-satunya metode yang dianggap paling tepat untuk menguji hipotesis mengenai hubungan sebab akibat (Mahmud, 2011). Jenis penelitian yang akan digunakan dalam penelitian ini adalah penelitian kuantitatif dengan desain Pre-Experimental Designs (nondesigns). Metode kuantitatif adalah metode penelitian yang berlandaskan pada filsafat positivisme, digunakan untuk meneliti populasi atau sampel tertentu, pengumpulan data menggunakan instrumen penelitian, analisis data bersifat kuantitatif atau statistik dengan tujuan untuk menguji hipotesis yang telah ditetapkan (Sugiyono, 2011).

Rancangan yang digunakan dalam penelitian ini adalah one group prestest-posttest design. Rancangan one group pretest posttest design terdapat pre-test, sebelum diberi perlakuan (Sugiyono, 2011). Adapun yang menjadi populasi ini adalah seluruh siswa kelas VIII SMP Negeri 16 Singkawang yang berjumlah 141. Pengertian populasi sebagai penelitian sabjek penelitian (Arikunto, 2013). Peneliti menentukan jumlah sampel dengan menggunakan teknik nonprobability sampling. Teknik nonprobability sampling adalah teknik pengambilan sampel yang tidak memberikan peluang/kesempatan sama bagi setiap unsur atau anggota populasi untuk dipilih menjadi sampel (Sugiyono, 2011). Adapun jenis probability sampling yang dipilih adalah purposive sampling. Purposive dilakukan dengan cara mengambil subjek bukan didasarkan random. Tetapi didasarkan atas adanya tujuan tertentu (Arikunto, 2013). Sampel yang akan diambil dalam penelitian ini adalah kelas VIII B dengan jumlah siswa sebanyak 35 orang.

Teknik pengumpul data dalam penelitian ini adalah teknik observasi langsung dan teknik komunikasi tidak langsung. Teknik observasi langsung adalah observasi yang dilakukan tanpa perantara (secara langsung) terhadap objek yang diteliti (Mahmud, 2011). Peneliti langsung terjun ke lapangan untuk memperoleh data yang diperlukan secara objektif. Teknik komunikasi tidak langsung merupakan teknik dengan mengunakan angket atau kusioner sebagai alat pengumpul data (Nawawi, 2015). Alat pengumpul data dalam penelitian ini adalah tes dan dokumentasi.

\section{HASIL DAN PEMBAHASAN}

\section{HASIL}

Hasil penelitian ini adalah untuk mengetahui pengaruh model pembelajaran reciprocal learning terhadap keterampilan menulis rangkuman isi buku ilmu pengetahuan populer pada siswa kelas VIII B SMP Negeri 16 Singkawang tahun ajaran 2016/2017. Adapun hasil yang diperoleh dari penelitian ini meliputi, hasil belajar siswa 
sebelum dan sesudah diterapkannya model pembelajaran reciprocal learning, dan seberapa besar pengaruh model pembelajaran reciprocal learning terhadap keterampilan menulis siswa pada materi menulis rangkuman isi buku ilmu pengetahuan populer.

Tabel 1. Data Hasil Pre-test dan Post-test

\begin{tabular}{|c|c|c|}
\hline Keterangan & Pre-test & Post- tes \\
\hline Jumlah & 1947 & 2808 \\
\hline Rata-rata & 55,62 & 80,22 \\
\hline
\end{tabular}

Dari Tabel 1 diketahui bahwa nilai rata-rata hasil tes keterampilan menulis rangkuman siswa mengalami peningkatan rata-rata pre-test sebesar 55,62 dan rata-rata post-test 80,22. Dengan demikian dapat disimpulkankan bahwa nilai tes keterampilan menulis rangkuman siswa meningkat setelah diberikan perlakuan dengan menggunakan model pembelajaran reciprocal learning.

Uji normalitas dilakukan bertujuan untuk mengetahui apakah data pre-test dan post-test berdistribusi normal atau tidak. Rumus yang digunakan adalah rumus chi kuadrat. Menentukan harga $\chi_{\text {tabel }}^{2}$ dari daftar dengan $=5 \%$ atau 0.05 dengan skor 9,488. Kriteria : Jika $\chi_{\text {hitung }}^{2}<\chi_{\text {tabel }}^{2}$ maka data berdistribusi normal. $\chi_{\text {hitung }}^{2}=3,717$ dan $\chi_{\text {tabel }}^{2}=9,488$. Karena nilai $\chi_{\text {hitung }}^{2}<\chi_{\text {tabel }}^{2}$ maka dapat disimpulkan bahwa data post-test berdistribusi normal.

Untuk mengetahui seberapa besar pengaruh model pembelajaran reciprocal learning terhadap keterampilan menulis rangkuman siswa kelas VIII B SMP Negeri 16 Singkawang, maka data yang diperoleh diuji dengan rumus effect size.

Tabel 2. Uji Effect Size

\begin{tabular}{|l|l|l|}
\hline Keterangan & Pre-test & Post-test \\
\hline Jumlah & 1947 & 2808 \\
\hline Rata-rata & 55,62 & 80,22 \\
\hline Standar deviasi & 11,34 & 7,97 \\
\hline
\end{tabular}

Dari Tabel 2 dapat diketahui bahwa nilai Effect Size adalah 3,08, berdasarkan kriteria Effect Size 3,08 terletak pada ES > 0,8 maka nilai Effect Size kategori tinggi. Karena nilai Effect Size kategori tinggi maka dapat disimpulkan bahwa model pembelajaran reciprocal learning berpengaruh terhadap keterampilan menulis rangkuman isi buku ilmu pengetahuan populer.

Uji Hipotesis dengan t-test.

$$
\begin{aligned}
\mathrm{t} & =\frac{X_{1}-X_{2}}{\sqrt{\frac{s_{1}^{2}}{n_{1}}+\frac{s_{2}^{2}}{n_{1}}-2 . r\left(\frac{s_{1}}{\sqrt{n_{1}}}\right)\left(\frac{s_{2}}{\sqrt{n_{2}}}\right)}} \\
& =\frac{55,62-80,22}{\sqrt{\frac{128,76}{35}+\frac{63,53}{35}-2,0,159\left(\frac{11,34}{\sqrt{35}}\right)\left(\frac{7,97}{\sqrt{35}}\right)}}
\end{aligned}
$$$$
=-11,36
$$

Berdasarkan perhitungan yang telah dilakukan didapatkan harga $t$ hitung sebesar -11,36 uji dua pihak bearti harga mutlak sehingga nilai (-) tidak dipakai. Selanjutnya harga $t$ hitung dibandingkan dengan $\mathrm{t}$ tabel $\left(\mathrm{dk}=\mathrm{n}_{1}+\mathrm{n}_{2}-2=35+35\right.$ $2=68$ ). Berdasarkan $\mathrm{dk}=68$, untuk kesalahan $5 \%$, maka harga $\mathrm{t}$ tabel $=2,000$. Ternyata harga $\mathrm{t}$ hitung $>$ dari harga $\mathrm{t}$ tabel $(11,36>2,000)$. Dengan demikian Ha diterima dan Ho ditolak.

\section{PEMBAHASAN}

Hasil dalam penelitian ini menunjukkan bahwa keterampilan menulis rangkuman siswa setelah menggunakan model pembelajaran reciprocal learning mengalami peningkatan. Hal ini dapat terlihat dari data hasil perhitungan pre-test 55,62, post-test 80,22.

Setelah dilakukan analisis hasil tes kemampuan menulis rangkuman siswa. Hasil penelitian menunjukkan bahwa pembelajaran bahasa Indonesia materi menulis rangkuman isi buku ilmu pengetahuan populer dengan menggunakan model pembelajaran reciprocal learning berpengaruh terhadap keterampilan menulis rangkuman. Hal tersebut ditunjukan dari hasil prê-test dan post-test siswa yang dihitung dengan rumus effect size dengan hasil 3,08 dengan kriteria berkategori tinggi.

Setelah analisis data dilakukan, kemudian dilanjutkan dengan uji hipotesis dengan menggunakan uji t. Hasil uji t didapatkan harga $\mathrm{t}$ hitung 11,38 kemudian dibandingkan dengan harga $\mathrm{t}$ tabel berdasarkan $\mathrm{dk}=68$ untuk kesalahan $5 \%$ maka didapatkan harga $\mathrm{t}$ tabel $=2,000$. Jadi dapat disimpulkan harga $\mathrm{t}$ hitung $>$ dari $\mathrm{t}$ tabel $(11,38>2,000)$. Maka dengan itu hipotesis Ha diterima dan Ho ditolak yakni "Terdapat pengaruh setelah digunakannya model pembelajaran reciprocal learning terhadap keterampilan menulis rangkuman pada siswa kelas VIII B SMP Negeri 16 Singkawang tahun ajaran 2016/2017."

\section{SIMPULAN DAN SARAN}

\section{SIMPULAN}

Berdasarkan hasil pengolahan data yang telah disajikan, maka secara umum dapat ditarik kesimpulan "Terdapat pengaruh model pembelajaran reciprocal learning terhadap keterampilan menulis rangkuman pada siswa kelas VIII B SMP Negeri 16 Singkawang tahun ajaran 2016/2017” secara khusus dapat ditarik kesimpulan sebagai berikut. (1) Kemampuan menulis rangkuman isi buku ilmu pengetahuan populer sebelum menggunakan model reciprocal learning pada siswa kelas VIII B SMP Negeri 16 Singkawang tahun ajaran 2016/2017 adalah dengan rata-rata nilai pre-test sebesar 55,62, (2) Kemampuan menulis rangkuman isi buku ilmu pengetahuan populer sesudah menggunakan model reciprocal learning pada siswa kelas VIII B SMP Negeri 16 Singkawang tahun ajaran 2016/2017 adalah dengan rata-rata nilai post-test sebesar 80,22, dan (3) Terdapat pengaruh model pembelajaran reciprocal learning terhadap keterampilan menulis rangkuman pada siswa kelas VIII B 
SMP Negeri 16 Singkawang tahun ajaran 2016/2017 berdasarkn uji t bahwa $t$ hitung lebih besar dari pada t tabel $(11,38>2,000)$ dengan effect size sebesar 3,08 dalam kategori tinggi.

\section{SARAN}

Peneliti memberikan beberapa saran dalam penelitian yang berjudul "Pengaruh Model Pembelajaran Reciprocal Learning Terhadap Hasil Belajar Keterampilan menulis pada Siswa kelas VIII B SMP Negeri 16 Singkawang Tahun Ajaran 2016/2017" sebagai berikut. (1) Model pembelajaran reciprocal learning dapat menjadi satu diantara alternatif dalam pembelajaran bahasa Indonesia untuk meningkatkan keterampilan menulis rangkuman, (2) Mengimplementasikan model pembelajaran reciprocal learning maka hendaknya menggunakannya sesuai dengan tujuan pendidikan agar dapat meningkatkan hasil, aktivitas, dan dapat meningkatkan prestasi belajar siswa dengan baik dan menerapkan model pembelajaran yang menarik dalam setiap proses belajar mengajar agar mendapatkan hasil yang optimal, (3) Dengan menggunakan model pembelajaran reciprocal learning harus lebih kreatif dalam menyajikan pembelajaran bahasa Indonesia agar pembelajaran bahasa indonesia lebih menarik dan tidak menimbulkan kebosanan bagi siswa, dan (4) Saat proses pembelajaran hendaknya memberikan arahan yang jelas kepada siswa agar siswa memahami jalannya pembelajaran dengan menggunakan model pembelajaran reciprocal learning dan melihat kegiatan siswa selama pembelajaran berlangsung.

\section{DAFTAR PUSTAKA}

Arikunto, Suharsimi. (2013). Prosudur Penelitian. Jakarta: Rineka Cipta.

Huda, Miftahul. (2015). Model-model Pembelajaran dan Pengajaran. Yogyakarta: Pustaka Pelajar.

Mahmud. (2011). metode penelitian pendidikan. Jakarta: Rineka Cipta.

Nawawi, Hadari. (2015). Metode Penelitian Bidang Sosial. Yogyakarta: Gadjah.

Ngalimun. (2016). Strategi dan Model Pembelajaran. Yogyakarta: Aswaja Pressindo.

Purnama, Risma. (2014). Cooperative Learning Implementasi dalam Perencanaan Pembelajaran. Pontianak: Stain Pontianak Press.

Saddhono, Kundharu dan St, Y. Slamet. (2012). Meningkatkan Keterampilan Berbahasa Indonesia (Teori dan Aplikasi). Bandung: Karya Putra Darwati.
Sugiyono. (2011). Metode Penelitian Pendidikan Pendekatan Kulitatif Kuantitatif R \& D. Bandung: Alfabeta. 